\title{
The Fluctuation Cycle of Mercury content in Early Cambrian Black Shales in Southern China and its Indication of Redox process
}

\author{
Guangyou Zhu ${ }^{1}$, PenguU WANG ${ }^{1}$, Tingting Li ${ }^{1}$ \\ ${ }^{1}$ Research Institute of Petroleum Exploration and \\ Development, PetroChina, Beijing 100083, China
}

Cambrian is an important transition period of geological history evolution and the sedimentary thick strata of early Cambrian black shale recorded the important information of this period. The set of $30 \sim$ $120 \mathrm{~m}$ thickness mudstone is developed stably and widely in South China, which is the important material of the study of marine redox environment and biological evolution. Black shale is especially developed in the Niutitang Formation of lower Cambrian in Tongren area of Guizhou province, which is an important target for shale gas exploration. It was found that the mercury $(\mathrm{Hg})$ content in this shale changed strongly, and the total organic content (TOC) fluctuated synchronously and the two have good positive relationship. Rare earth element and mercury isotope data indicated that the sedimentary process of mudstone in the lower part of the Niutitang Formation was influenced by hydrothermal activity during the same period, which boosted biological prosperity and organic matter enrichment and hence led to mercury enrichment. Black mudstone of TOC, Hg content and trace elements as a whole indicate the process of water body on the longitudinal water by reducing environment to the oxidation gradually in longitudinal. But there is an obvious three phase of the cycle fluctuations namely the reduction - weak oxidation reduction-weak oxidation-reduction-oxidation process. It reveals the sedimentary water body is influenced by multiple stage of the hydrothermal activity and it also revised the accepted evolution model which showed the early Cambrian's environment gradually transition from reduction environment to the oxidation environment. 